\title{
Motivations and barriers to the prolonged use of clothing
}

Jade Whitson-Smith, University of Huddersfield, j.e.whitson-smith@hud.ac.uk

\begin{abstract}
With increased awareness of environmental issues, and of ethical consumption, the fashion has been trying to address ethical issues in its supply chain, and on consumer behaviour. One approach to reducing the environmental impact of garment consumption is to change the way consumers behave. The prevailing strategies for behaviour change utilized within sustainable fashion have fallen into two categories: the provision of information, such as social media campaigns, and the creation of new garments using design strategies such as 'design for durability'. However, these strategies are based on assumptions, rather than empirical understanding of what motivates consumer garment use, or the mechanics of behaviour change. This article focuses on one particular environmentally desirable behaviour: wearing garments for longer, and the factors influencing this behaviour. The findings provide insights into where improvements could be made.
\end{abstract}

A quantitative wardrobe study was undertaken with female consumers in the United Kingdom. The purpose of the study was to explore the motivations and barriers to a selection of environmentally desirable garment-use behaviours, including wearing garments for longer. From this study, behavioural motivations were compiled. The predominant factors motivating prolonged wear were comfort and good fit of garments. The predominant factor acting as a barrier was change in circumstances, which changed consumer's perceptions of how appropriate garments were for their perceived identity.

The implications of these results are twofold. Changes in personal circumstances are inevitable for all consumers, and something that designers cannot influence. This suggests that alongside promoting prolonged wear, it is critical to guide consumers 
towards shifting ownership of unworn garments to new users. There is also an opportunity for designers and researchers to further explore comfort and fit of garments, but these factors are highly individualistic, which suggests that mass production may be detrimental to promoting prolonged wear.

\section{Keywords}

garment use

garment discard

environmental impact

motivations

barriers

\section{Introduction}

The rise of cheap fast fashion has meant that young women, and people of low incomes are able to consume and discard fashionable clothing on a regular basis (Buckley and Clark, 2017). Yet despite increased awareness of the wider implications of ethical issues associated with fashion and beauty, the industry tended to compartmentalize the ethical agenda and privilege mostly particular aspects such as fair trade and sustainability, to the exclusion of issues such as animal welfare, toxic cosmetics and damaging role models offered by both industries (e.g. Tseëlon 2011). The movement to encourage ethical practices came from NGOss and anti-consumerism campaigns had the effect of increasing sustainable fashion labels entering the market, but not in reducing consumption. In fact, mainstream fashion 
practices remain environmentally unsustainable, while opaque and lengthy fashion supply chains often mask exploitative and dangerous production practices. The debate on ethics in fashion tended to focus on production practices and consumption patterns, but not on use and discard of garments. Textile waste poses a significant environmental threat, and has become increasingly problematic with fast fashion cycles accelerating to meet shorter lead times. For example, 21 billion pounds of waste textiles are sent to landfill each year in the US, from the textile industry offcuts and from consumers discarding used clothing as well as new, unworn clothing (Cline 2013). In China, the world's largest manufacturer of garments, 26 million tonnes of textiles are discarded each year (Redress 2015).

This article looks at managing waste at the individual consumer level, and explores the existing factors motivating consumers to wear garments for longer, and the barriers preventing this. Developments in behavioural understanding offer insights into how behaviour change could be motivated.

Garment consumption is defined as a series of phases including pre-purchase, purchase, use and discard (Winakor 1969). Garment consumption behaviour is understood to be responsible for significant environmental impact, including energy and water use, chemical contamination and material waste (Fletcher 2008). Despite these impacts, relatively little is known about garment consumption beyond the point of purchase (Mohr, Webb and Harris 2001). This is particularly true of the use phase, which includes intimate activities such as wearing, storing, laundering and repairing garments.

Although understanding of this phase of garment consumption is limited, it is apparent that the average life of a garment has steadily decreased. The average life of a garment in the United Kingdom is now 27 months (WRAP 2012). The speed at which fashion is consumed and discarded has been influenced by the ascent of fast fashion: low cost, on- 
trend garments sold by value and high street retailers. The fast fashion sector doubled in growth between 2000 and 2010, and as of 2010 made up one-fifth of the UK market (DEFRA 2010). Only utilizing garments for short periods and discarding them before they are worn out amplifies the environmental impact of garment production.

\section{Garments use and discard}

Environmentally desirable behaviours are the optimal behaviours consumers could undertake to reduce their impact on the environment. In the literature, evidence-based suggestions on how consumers should behave are limited. However, as shown in Figure 1, the Well Dressed report (Allwood et al. 2006) suggested a range of behaviour changes that consumers could adopt to reduce their environmental and social impacts.

One suggested behaviour is wearing garments for longer.

- Buy second-hand clothing and textiles where possible.

- Buy fewer but longer-lasting garments and textile products.

- When buying new products, choose those made with least energy and least toxic emissions.

- Only buy products made by workers paid a credible living wage with reasonable employment rights and conditions.

- Lease clothes that would otherwise not be worn to the end of their natural life.

- Wash clothes less often, at lower temperatures and using eco-detergents, hang-dry them and avoid ironing where possible.

- Extend the life of clothing and textile products through repair.

- Dispose of used clothing and textiles through recycling businesses who would return them for second-hand sale wherever possible, but otherwise extract and recycle the yarn or fibres. 
Figure 1: What would the ideal consumer do? (Allwood et al. 2006, pg 68).

Extending the life of a garment has a potential impact on reducing discards and producing replacements, but is only effective if there is also a reduction in purchases (Allwood et al. 2006). The use of garments has associated impacts such as the energy, water and chemicals used in laundering (Fletcher 2008); clearly, these increase when a garment has an extended life. However, for some garments it is possible that extending their life can reduce their overall environmental impact more than reductions in washing and drying (Sandin, Zamani and Peters 2015).

Garments are being discarded before they are physically worn out. In product-based research, premature discard has been linked to fashion change or change in circumstances that deem a product as no longer needed (Mont 2002). A meta-analysis of garment discard studies found that the three main reasons individuals discarded garments were wear-and-tear, fit or size and fashion: the later associated with matters of taste or of boredom (Laitala 2014).

Garments are a visible identity marker. Identity is not fixed but is in a continual process of emerging (Kaiser 1997), therefore as identities shift garments may no longer fit with that identity. Klepp and Laitala (2015) suggest that fashion change has less influence on garment behaviour than may have been previously assumed. Individuals attribute their taste changes to factors other than fashion. In her extensive work on what personal information people are communicating about themselves through their clothes, Tseëlon (1989) found that style, occasion, level of confidence and the desire to blend in or stand out, for example, were more influential than fashion change. Woodward, using ethnographic methods, supports these findings, recognizing that changes in an individual's practices are more likely to come from other everyday sources rather than the influence of fashion change (Woodward 2015). 
For many consumers, reducing the level of garment discard would mean a change in behaviour from short-lived interactions with garments to wearing garments for longer. Formulating interventions to change behaviour is complex and involves understanding the motivations behind our actions. Within sustainable fashion it has been assumed that providing information to consumers on how to behave would motivate change. However, this assumption is not supported by the fact that ethical fashion remains a niche market (Crane 2016), and over emphasizes the influence of information on behaviour.

Some of the flaws in information provision include: information is easily forgotten (Jelsma 2003); individuals may not take personal responsibility for changing environmental impact (Sawitri, Hadiyanto and Hadi 2015); and an individual's attitude may be outweighed by other factors such as context and personal capabilities (Stern 2000). It is not enough to provide individuals with information on the consequences of behaviours; they have to subscribe personally to this information. The ascription and acceptance of responsibility occurs when individuals both understand the impact of their behaviour and believe that they are responsible for changing their actions to reduce that impact (Schwartz 1977).

The term pro-environmental behaviour refers to behaviours where individuals act with the intention of having a positive impact on the environment. Some studies have started to identify that environmentally desirable behaviours do not always occur with intent and can be 'accidental' (Fisher et al. 2008a; Woodward 2015). In the absence of pro-environmental intent, other influences are motivating behaviours that are, nevertheless, environmentally desirable. In addition, pro-environmental intent can be misplaced onto an environmentally detrimental behaviour.

In the behavioural sciences, the attitude-behaviour gap is acknowledged as evidence that behaviour is influenced by factors beyond attitudes. Increasingly, businesses 
are recognizing that they need to take note not only of what consumers believe in, but equally what they choose to act upon (Fukukawa and Ennew 2010). In particular, Stern's Attitude-Behaviour-Context (ABC) theory draws attention to the influence of context on behaviour. The theory suggests that if behaviours are not supported by the context and personal capabilities, then there is a weaker dependence on attitudinal factors (Stern 2000). This theory can be applied to fashion consumption, which has historically been influenced by contextual factors.

Within the field of fashion, it has often been left to designers, or design-led researchers, to explore solutions to the environmental impacts of garment consumption. Consumer behaviour is complex, and many of the variables influencing it are beyond a designer's control (Jääskö and Mattelmäki 2003). The difficulty in using the design of a garment to change behaviour is the inability to accurately predict changing contextual factors, such as the economy, which impacts on use (Bras 1997). A range of sustainable fashion design strategies have been developed (Gwilt 2014) based on the assumption that the physical characteristics of a garment have the most significant influence on consumer behaviour. This assumption is not supported by empirical study.

\section{A wardrobe study}

In order to investigate the factors influencing a range of environmentally desirable garmentusage behaviours, an in-depth qualitative wardrobe study with seventeen participants was undertaken. Prolonging the use of clothing was one of the behaviours included in the study.

The wardrobe study largely used qualitative methods, which are inductive and concerned with exploration and theory generation (Johnson and Onwuegbuzie 2004). There were three strands to the wardrobe study: a pre-audit questionnaire, a wardrobe audit and a garment interview. They were designed to identify the significant influencing factors on 
post-purchase garment behaviour. The aim was to generate theory from the data, utilizing a grounded theory approach to data collection (Strauss and Corbin 1998).

The studies were undertaken sequentially, with the garment interview as the final stage. It consisted of semi-structured questioning regarding the garments the participants had brought with them. The informal nature of the interviews allowed the researcher to build a rapport with the participants and allowed them to share 'off topic' insights, which often provided useful context to their garment consumption. The three phases of the wardrobe study are shown in Figure 2.

Pre-audit
on the participant (e.g. age, ethnicity, income), their garment
purchasing habits and environmental viewpoint. This is similar
to the environmental viewpoint questionnaire conducted by
Fisher et al. (2008b) within their Public Understanding of
Sustainable Clothing study. The pre-audit questionnaire was
used to categorize participants and examine the influence of
contextual factors.
Following the pre-audit questionnaire, an audit pack was posted
to participants. They were asked to complete a wardrobe audit
worksheet at home. This involved self-auditing the garments that
they wore regularly using a wardrobe audit worksheet. The
worksheet asked them to record garment type, brand, fibre




content, fabric, colour, pattern, details, cut, age and damage. A
help sheet was provided to guide them.
Participants were asked to bring six garments from their
wardrobe:
1. owned for a long time
2. emotionally attached to
3. never wear
4. wear frequently
क. recently purchased
(infrequently or never worn) garments. Participants were
6. likely soon to discard
These garments were selected to give an overview of the

Figure 2: The three stages of the wardrobe study method.

Voluntary sampling was utilized, which controlled for a bias towards participants with an existing interest in the research topic. Only three of the participants reported having an 
interest in fashion. The research sample was made up of females between the ages of 18 and 75, living in the United Kingdom.

The wardrobe study was analysed using techniques from the grounded theory approach. Grounded theory approaches the analysis of data as a method for generating and discovering theory (Strauss and Corbin 1998). There were three types of data for analysis: quantitative data from both the questionnaires and the audits and qualitative interview transcript data. Qualitative thematic analysis was used to analyse the interview data. Following the principles of grounded theory, theorizing happened after the data analysis (Goulding 2002).

\section{Results}

Figure 3 represents the motivations for and barriers to wearing a garment for longer that emerged from the wardrobe study.

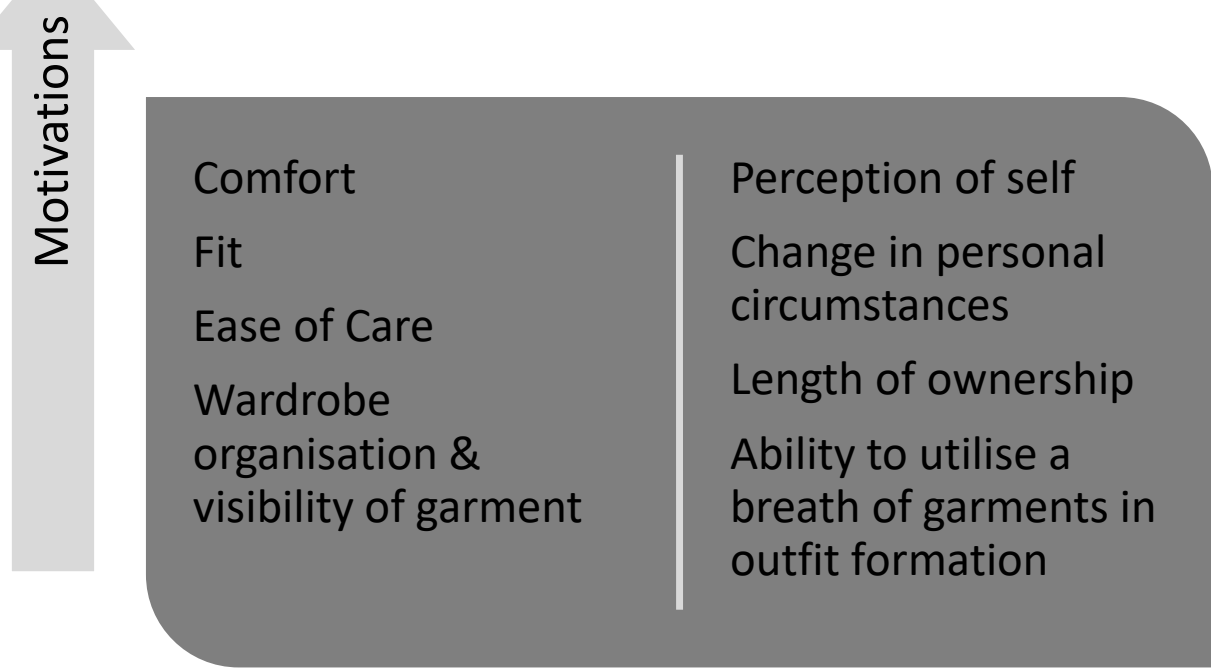


Figure 3: Motivations and barriers to wearing garments for longer.

The motivations that supported the long-term wear of garments tended to focus on the material attributes of the garments. There was a positive relationship between the clothing that the participants liked, wore frequently and used for a long time, and how comfortable they felt when wearing these garments. With regards to clothing, comfort could be defined in two ways: the physical comfort determined by the material aspects of the garment or the psychological comfort determined by the individual's approval of a particular style. Both perspectives on comfort are highly subjective to an individual's beliefs and physical characteristics.

Similar to comfort, the way a garment fitted an individual impacted on wear: a wellfitting garment is more likely to be worn. When mentioning a well-fitting garment, participants lamented the difficulty of finding garments that fit them; they had often spent a long time looking for the right fit for their body shape and size. Garments that did fit well were valued in the wardrobe.

These results support the research of Niinimäki (2017) who found that for women, the main reasons for longevity of garments were closeness of fit $(85 \%)$ and other material properties of the garments (quality $74 \%$, liking the material $71 \%$, and liking the style $69 \%$ ).

'... if they continue to fit me I tend to keep them for quite a while unless the fashion really changes...' 
Ill-fitting garments were dealt with in a different way than other inactive clothing; they were rarely kept in the wardrobe inventory and were destined to be discarded much quickly than a garment that was inactive for any other reason. An exception was any garment that was kept to inspire weight loss.

In general, the garments the participants wore frequently were easy to care for, described as being machine washable and requiring little or no ironing.

'Other than that I really like it, because it's really easy to wear, it's really easy to wash.'

Difficulties in the care process slowed down the garment's return to the wardrobe after use, and this seemed to dissuade users because of the associated after-care.

Most of the participants organized their wardrobe in some way, but some did not. Organization meant access to clothing was easier, as they knew where to look for particular garments, and it reduced the likelihood of garments being forgotten or inactive. Although this might not always lead to individuals wearing garments for longer, it gave garments more exposure and, therefore, increased the probability of wear.

\section{Barriers to wearing garments for longer}

The barriers that prevented long-term wear were less attributed to the garment itself, and were based more on the participant's situation, capabilities and attitudes. Style choices arose from the individual's attitudes and beliefs about their identity. If an individual felt a garment was 'not me', they would not feel motivated to wear it. Individual perceptions of identity change, so that clothing once felt to be appropriate can cease to be so. Participants recognized 
that their clothing preferences changed over time, but felt this process was quite informal, without any major impetus for decision making. This conclusion supports Tseëlon's research (1992) which identified that on the whole, women tended to prefer clothes that represent a true picture of themselves.

'I like to get things that are a lot more jazzy [sic] now, whereas I used to go for really plain clothes.'

Although personal style changed, very rarely did a participant attribute this to changes in fashion. In fact, the word 'fashion' itself was rarely used in the interviews. More prevalent were examples of the participant's age impacting on their perception of what was appropriate for them to wear.

'I'm getting a bit older now, so I probably wouldn't wear anything... I'm probably steering towards not so small, revealing dresses now when I go out. I prefer to cover up a bit more.'

'I like it, but not as much as I used to. I mean obviously, it is quite old now, and you do change how you want to be perceived.'

As participants aged, they felt they needed to wear clothing that was less revealing and more reserved. This led to clothing that was previously worn becoming inactive. 
A change in circumstances could result in garments becoming inactive. Many of the participants mentioned having a 'work wardrobe' separate from the clothing they would wear socially. Work clothing had been carefully selected to give the right impression and be suitable for their role. Such clothing is constructed around an identity or an identity projection, which interestingly involves an introjection of what the individual perceives as being appropriate or expected through other people's eyes. The potential for interplay between notions of what is acceptable, respectable and expected and how far this can be inflected as an expression of personal identity is an interesting question.

I'm trying to generate a certain kind of impression unfortunately, and it just helps people put me in a box I think. Hopefully that right one! I'm kind of going for librarian.'

This kind of clothing, which facilitates the individual in playing a role, may no longer be required when the role is over. One participant had a pair of work trousers she no longer wore; they had been used when her role at work involved site visits and required practical clothing. Her current role was senior and office based, therefore she felt smart dresses were more appropriate. Not wearing these trousers reflected two factors; her situation had changed and, therefore, her belief about what styles she should wear or not wear had changed. Moving into a new life situation often requires new clothes (Kaiser 1997).

The 'worn regularly' garments that were brought to the interview had been in the participants' wardrobe for varying lengths of time, from one month to twenty years. This indicates that garments can be worn regularly regardless of how long they have been in the wardrobe. Despite this, the audit indicates that most of the garments that the participants wore regularly had been owned for less than two years (see Figure 4). This suggests that the longer 
an individual owns a garment, the less likely it is to be worn, which makes the passage of time a significant barrier.

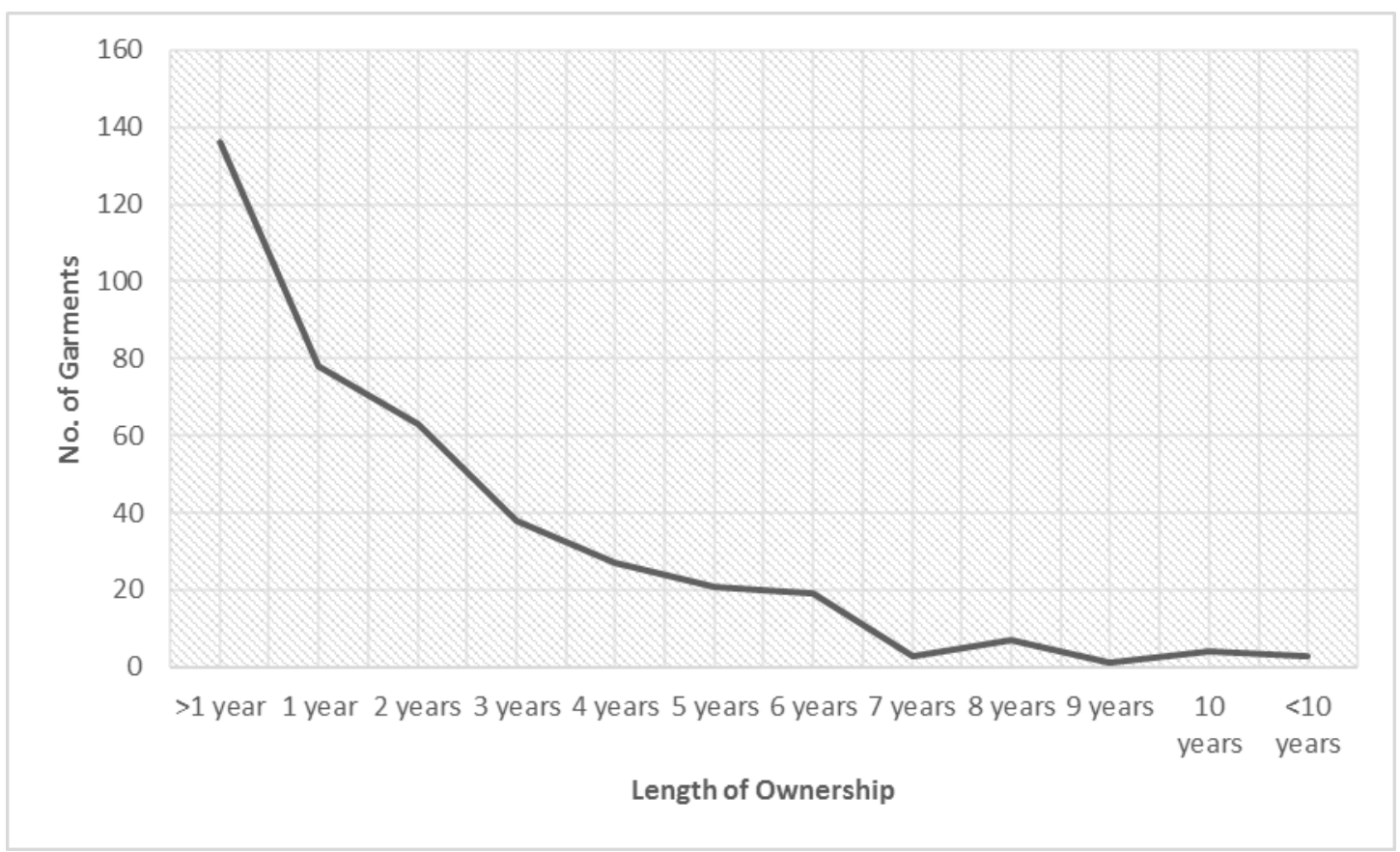

Figure 4: The length of ownership of clothing worn regularly by the wardrobe audit participants.

Garments that coordinated with lots of other items in the wardrobe were appreciated by the participants; there was frustration with garments that were difficult to partner with other items, which would often remain inactive.

Some factors were conspicuous by their absence from the results: pro-environmental intent, emotional attachment and fashion change. The absence of pro-environmental intent demonstrates that, in the case of prolonging the use of clothing, environmentally desirable behaviour can occur without intent. Fostering emotional attachment has been suggested as one strategy for prolonging the use of garments. Amongst the participants in this study an 
interesting distinction emerged: while emotional attachment could extend ownership, it did not extend use. Change in fashion was not mentioned as a barrier to wearing garments for longer. In fact, a change in garment preference based on style was more likely to arise from personal context rather than the wider context of fashion change.

\section{Discussion}

The results of the wardrobe study support Stern's theory that behaviour has a stronger dependence on context than on attitudes. The factors influencing behaviour could be grouped into two categories: personal context and physical characteristics of garments. It appears that both of these categories need to be supportive in order for prolonged garment use to occur.

In order for an individual's context to be supportive of prolonging use of garments they would need to experience neither changes in personal circumstances, nor developments in their identity. This would be a highly unlikely. Some changes are inevitable, such as ageing or professional role, and many others are unpredictable. Therefore, a more realistic strategy would be to promote more efficient shifts in the ownership of garments. This could be facilitated through endeavours such as clothing exchanges, or developments in infrastructure supporting the resale of used clothing. Such activities do not traditionally fall under the responsibility of the fashion designer, and therefore signal the need for other stakeholders to contribute to sustainable fashion strategies.

The capacity of a garment to maintain and endure prolonged use depends upon a set of individualistic factors. Each consumer is likely to have different needs and preferences with regards to fit and comfort. Although most consumers are fairly used to accommodating themselves to the available parameters, it is perhaps inevitable that mass-produced garments will not meet these exacting requirements. 
The results of the study indicate that design strategies that rely purely on the physical characteristics of garments are likely to have a relatively modest influence on consumer behaviour. Most importantly, they also indicate that pro-environmental attitudes are not needed in order to undertake environmentally desirable behaviour. Therefore, many current approaches to 'sustainable fashion' may be misplaced.

\section{Conclusions}

The study identified that pro-environmental intent was not significant in motivating environmentally desirable behaviour. This stresses the importance of going beyond providing information to change behaviour.

Variables that constructed the personal context of an individuals' behaviour were some of the most resilient influences. It may prove very difficult, or impossible, to change some of these variables. It is also possible for these variables to change suddenly, due to external factors, creating a change in behaviour. Such a change could be desirable or undesirable.

This study found that physical characteristics of garments are not the only factor influencing behaviour, and therefore should not be utilized as the sole strategy for changing behaviour. Furthermore, the effectiveness of one design strategy - 'design for emotional attachment' - was disputed. Emotional attachment was revealed to have limited connection to the material properties of the garment, and emotional attachment tended to motivate longterm storage rather than prolonged wear.

Solutions to issues of fashion and the environment should not be the sole responsibility of the fashion designer. Other agencies need to look at how they can contribute to promoting environmentally desirable behaviour in the fashion sector. The emphasis should 
be on creating supportive contexts to facilitate prolonging the wear of garments. In terms of material characteristics of garments, the study points at the potential for further research into garment fit, comfort and ease of care. These factors are not currently adequately explored.

\section{References}

Allwood, J., Laursen, S., Malvido de Rodriguez, C. and Bocken, N. (2006), Well dressed?

The Present and Future Sustainability of Clothing and Textiles in the United Kingdom.

University of Cambridge, Cambridge.

Buckley, C., \& Clark, H. (2017), Fashion and Everyday Life: London and New York.

London: Bloomsbury Academic.

Cline, E. L. (2013), Overdressed: The Shockingly High Cost of Cheap Fashion (2nd ed.), New York, NY: Portfolio/Penguin.

Crane, D. (2016), 'The puzzle of the ethical fashion consumer: Implications for the future of the fashion system', International Journal of Fashion Studies, 3:2, pp. 249-65.

Fisher, T., Cooper, T., Woodward, S., Hiller, A. and Goworek, H. (2008a), Public

Understanding of Sustainable Clothing: Summary, London: Nottingham Trent University and Sheffield Hallam University.

(2008b), Public Understanding of Sustainable Clothing. Appendix to a Research Report Completed for the Department for Environment, Food and Rural Affairs by Nottingham Trent University and Sheffeild Hallam University, London: Nottingham Trent University and Sheffield Hallam University.

Fletcher, K. (2008), Sustainable Fashion \& Textiles: Design Jouneys, London: Earthscan. 
Gatersleben, B., Steg, L. and Vlek, C. (2002), 'Measurement and determinants of environmentally significant consumer behavior', Environment and Behavior, 34:3, pp. 335362.

Fukukawa, K., \& Ennew, C. (2010), 'What we believe is not always what we do: An empirical investigation into ethically questionable behavior in consumption', Journal of Business Ethics, 91:1, pp. 49-60.

Gwilt, A. (2014), A Practical Guide to Sustainable Fashion, London: Fairchild Publications. Jääskö, V. and Mattelmäki, T. (2003) 'Observing and Probing' Proceedings of the 2003 international conference on Designing pleasurable products and interfaces - DPPI '03, pp. 126-131.

Jelsma, J. (2003), 'Innovating for Sustainability: Involving Users, Politics and Technology', Innovation: The European Journal of Social Science Research, 16:2, pp. 103-116.

Johnson, R. B. and Onwuegbuzie, A. J. (2004), 'Mixed Methods Research: A Research Paradigm Whose Time Has Come', Educational Researcher, 33:7, pp. 14-26.

Kaiser, S. B. (1997), The Social Psychology of Clothing: Symbolic Appearances in Context, New York: Fairchild Publications.

Klepp, I and Laitala, K. (2015), 'Consumption stories: The force of the ordinary', in K. Fletcher and M. Tham (eds), Routledge Handbook of Sustainability and Fashion, Oxon: Routledge, pp. 121-130.

Mohr, L., Webb, D. and Harris, K. (2001), 'Do consumers expect companies to be socially responsible? The impact of corporate social responsibility on buying behavior', Journal of Consumer Affairs, 35:1, pp. 45-72.

Niinimäki, K. (2017), 'Aesthetical or rational: Gender differences in ethical fashion 
consumption', Journal of Consumer Ethics, 1:2, pp. 7-18.

Redress. (2015), The EcoChic design award's 5 year legacy puts waste back into fashion. Eco-Business. http://www.eco-business.com/press-releases/the-ecochic-design-awards-5year-legacy-puts-waste-back-into-fashion/ Accessed 14 May 2018.

Sandin, G., Zamani, B. and Peters, G. (2015), Environmental Assessment of Swedish Fashion Consumption. Sweden: Mistra Future Fashion Consortium.

Stern, P. C. (2000), 'Toward a coherent theory of environmentally significant behavior', Journal of Social Issues, 56:3, pp. 407-24.

Strauss, A. and Corbin, J. (1998), Basics of Qualitative Research: Techniques and Procedures for Developing Grounded Theory, California: SAGE Publications.

Tseëlon, E. (1989), Communication via Clothing, PhD thesis, University of Oxford. (1992), 'Self presentation through appearance: A manipulative vs. a dramaturgical approach, Symbolic Interactlon, 15:4, pp. 501-5I3. (2011), 'Introduction: a critique of the ethical fashion paradigm', Critical Studies in Fashion \& Beauty, 2, pp. 3-68.

Winakor, G. (1969), 'The process of clothing consumption', Journal of Home Economics, 61:8, pp. 629-34.

Woodward, S. (2015), ‘Accidentally sustainable? Ethnographic approaches to clothing practices', in K. Fletcher and M. Tham (eds), Routledge Handbook of Sustainability and Fashion, Oxon: Routledge, pp. 131-38.

WRAP (2012), 'Valuing our Clothes: The True Cost of How we Design, Use and Dispose of Clothing in the UK'. 
